\title{
REPRESENTAÇÕES SOCIAIS DE ESTUDANTES DE CORREÇÃO DE FLUXO ESCOLAR SOBRE LEITURA
}

\author{
SOCIAL REPRESENTATIONS OF SCHOOL FLOW CORRECTION STUDENTS \\ ABOUT READING
}

Nathalie Sena da Silva ${ }^{1}$

Diógenes José Gusmão Coutinho²

Allyne Evellyn Freitas Gomes ${ }^{3}$

RESUMO: Os/as educandos/as carregam de modo subjacente aos comportamentos diante da leitura as concepções que têm sobre ela. Essas representações podem mudar conforme novas vivências. Esta pesquisa parte da hipótese que discentes em atraso escolar agem passivamente frente à leitura por terem representações ancoradas em ideias negativas sobre ela, baseadas em experiências desagradáveis, dificultando a alfabetização. Essa conjectura originou o objetivo deste estudo: compreender as representações sociais de leitura elaboradas por oito estudantes - não alfabetizados e repetentes - de uma turma de correção de fluxo da rede municipal do Recife. Nessa perspectiva, adotou-se como referencial teórico-metodológico a Teoria das Representações Sociais (TRS) pela preocupação com a interrelação entre sujeito e objeto e como é construído o conhecimento do senso comum. Realizou-se um estudo de caso como estratégia metodológica de investigação-ação, com abordagem qualitativa e modalidade etnográfica. Os instrumentos de produção de dados foram a observação participante, para verificação das relações do grupo com a leitura, e as entrevistas, para averiguação das transformações das representações. O exame dos dados pautou-se na análise de conteúdo. Os resultados revelaram quatro categorias: concepções ancoradas em aspectos positivos, concepções ancoradas em aspectos negativos, concepções ancoradas na escolarização e concepções ancoradas no letramento. Verificaram-se transformações nas representações devido às novas experiências pedagógicas. No final do ano não havia indicadores ancorados em ideias negativas. Conclui-se que mudanças nas representações impactaram positivamente na aprendizagem. Este estudo deixa sua contribuição ao abordar as relações entre as representações de um objeto (leitura) e a sua aprendizagem (alfabetização), impulsionando reflexões sobre às colaborações da TRS à educação, atribuindo um olhar psicossocial ao processo educativo e às dificuldades presentes nesse percurso.

\footnotetext{
I Mestre em Ciências da Educação pela Christian Business School. Especialista em PsicopedagogiaEscolar(Faculdade Joaquim Nabuco) e Pesquisa Avançada em Educação (Faculdade Alpha). Graduada em Pedagogia pela UFPE. Professora nas redes municipais de Igarassu-PE e de RecifePE.E-mail: liesenar@yahoo.com.brhttps://orcid.org/oooo-ooo2-5932-9666

${ }^{2}$ Doutor em Biologia Vegetal pela UFPE. Professor Universitário. E-mail: gusmao.diogenes@gmail.com

3 Mestre em Psicologia pela UFPE. Professora universitária. E-mail: allyne.evellyn@gmail.com https://orcid.org/oooo-0oo2-6564-7249
} 
Palavras-chave: Alfabetização. Leitura. Repetência. Correção de Fluxo Escolar. Teoria das Representações Sociais.

ABSTRACT: The learners carry underlying the behavior towards reading the conceptions about it. These representations may change according to new experiences. This research is based on the hypothesis that students in backwardness act passively in reading as they have representations anchored in negative ideas about reading, based on unpleasant experiences, making literacy difficult. This conjecture originated the objective of this study, which is to understand reading social representations elaborated by eight students - non-literate - of a school flow correction class in Recife. In this perspective, the Theory of Social Representations (TRS) was adopted as a theoreticalmethodological reference point because of the interrelationship between subject and object and how common sense knowledge is constructed. A case of study was developed as a methodological strategy for action research, with a qualitative approach and ethnographic modality. The instruments of data production were the participant observation, to verify the group relations with reading, and the interviews, to verify the transformations of the representations. The data examination was based on content analysis. The results revealed four representational categories: conceptions anchored in positive aspects, conceptions anchored in negative aspects, conceptions anchored in schooling and conceptions anchored in literacy. There have been transformations in the representations due to the new pedagogical experiences. By the end of the year there were no indicators anchored in negative ideas. It is concluded that the hypothesis was confirmed. Changes in representations positively impacted learning. This study leaves its contribution in addressing the relations between the representations of an object (reading) and its learning (literacy), stimulating reflections on the collaborations of the TRS to the education, attributing a psychosocial look to the educational process and the difficulties present in this course.

Keywords: Literacy. Reading. Repetition. School Flow Correction. Theory of Social Representations.

\section{INTRODUÇÃO}

A motivação para realização de uma pesquisa surge a partir de vivências sociais que mobilizam os/as pesquisadores/as de forma conectada a percepção de sua relevância intelectual (DESLANDES, 2007). A atuação docente em turmas de correção de fluxo escolar, desde o ano de 2012 na rede municipal de ensino do Recife-PE, proporcionou o contato com a realidade que evidencia o quão é elevado o número de estudantes que apresentam distorção idade-série, devido às dificuldades relacionadas à leitura e/ou por ainda estarem em processo de alfabetização. Nas primeiras interações com as turmas é possível observar insegurança, medo e até recusa, por parte dos/as alunos/as, durante as atividades de leitura de textos verbais, não verbais e pseudoleituras (SILVA; GOMES, 2019). Diante desse cenário, surgiram inquietações para construção deste trabalho, que podem ser condensadas por meio das subsequentes questões: "O que estudantes não alfabetizados, em situação de atraso escolar, pensam sobre a leitura? De que forma, o que pensam sobre a leitura interfere em sua aprendizagem? Suas representações sobre leitura podem mudar ao longo do ano letivo e favorecer a alfabetização?”. A partir das indagações expostas constatou-se a pertinência da realização de um estudo de caso 
etnográfico (ANDRÉ, 2012) conduzido em consonância com a ideia de professor/a pesquisador/a, cuja aproximação com a realidade investigada é vantajosa tanto para produção de dados quanto para proficuidade dos resultados obtidos (ZEICHNER, 1998).

Conhecer o que os/as estudantes pensam acerca da leitura pode ajudar no direcionamento do trabalho docente, especialmente no que concerne aos/às educandos/as que apresentam dificuldades no processo de alfabetização, pois as representações sociais "ajudam a decodificar a vida cotidiana" (ALEVATO, 1999, p.9I), explicitando o papel dos significados no processo de simbolização. Sobre o fato de se contemplar o olhar do alunado em situação de atraso escolar, um estudo introdutório do estado da arte da pesquisa sobre o fracasso escolar apontou como aspecto positivo que

\footnotetext{
São pesquisas (...) em que os pesquisadores ultrapassam a tradição da fala sobre os sujeitos da pesquisa do fracasso escolar para incluir a fala dos participantes da vida escolar, analisadas por meio de procedimentos não-quantitativos de análise de discurso. (ANGELUCCI et al., 2004, p. 65)
}

Este artigo, que apresenta um recorte de uma dissertação de mestrado, promove a discussão da relevância e das interferências das representações sociais no ensino e na aprendizagem da leitura, visando contribuir também com a ampliação das reflexões relativas ao universo de culpabilizações que envolvem a temática do fracasso escolar. A intenção de apresentar contribuições acerca da realidade que envolve o analfabetismo de crianças escolarizadas e repetentes em situações de leitura, através das lentes da Teoria das Representações Sociais, é a justificativa de ordem acadêmica deste trabalho (DESLANDES, 2007). A hipótese estabelecida para a presente pesquisa é que os/as educandos/as demonstram atitudes de rejeição e passividade nos momentos de leitura por terem construído representações ancoradas em ideias negativas acerca do ato de ler a partir de experiências desagradáveis envolvendo a leitura. Fato que dificultaria o processo de alfabetização e assumiria um caráter cíclico no qual vivências negativas envolvendo a leitura promovem a construção de representações ancoradas em ideias negativas sobre o ato de ler, que originam atitudes de passividade, recusa e vergonha. A hipótese tem fundamento na ideia de que as representações sociais possibilitam aos sujeitos interpretar e conceber elementos da realidade para atuar em relação a eles (MOSCOVICI, 2015). Como as representações sociais são elaboradas e difundidas por meio da interação entre as pessoas em ações cotidianas de comunicação, podem ser reformuladas com base em representações prévias ou contra elas (MOSCOVICI, 2015). Desta forma, pressupõe-se que práticas pedagógicas lúdicas e significativas realizadas de modo sistemático envolvendo a leitura podem possibilitar a transformação das representações ancoradas em ideias negativas sobre o ato de ler em representações ancoradas em ideias positivas, favorecendo a alfabetização. Nessa perspectiva a transformação inversa também poderia ocorrer: o/a aluno/a pode ter representações ancoradas em aspectos positivos e, no contato com vivências desfavoráveis à prática da leitura, construir representações negativas. Conhecer o que os/as aprendizes pensam sobre a leitura e os impactos disso pode colaborar com a condução da prática docente (CHAIB, 2015), especialmente nos casos de estudantes que não aprenderam a ler na idade recomendada e sofrem com o estigma da repetência. No que se refere aos/às estudantes considerados dentro do padrão de aprendizagem da leitura, podem-se reforçar situações que contribuem com a construção de representações positivas para que não passem a ser negativas e prejudiquem o desempenho escolar futuramente. Buscou-se investigar e analisar como os/as educandos de uma turma de correção de fluxo lidam com o ato de ler na sala de 
aula, comparando suas ações com o que foi revelado durante os momentos de entrevistas e observações, acompanhando as possíveis transformações dessas representações para discutir a relevância e interferência das representações sociais nos processos de ensino e aprendizagem da leitura.

O estudo bibliográfico realizado por Silva (2017), com o intuito de pesquisar os fundamentos teórico-metodológicos mais utilizados nas pesquisas com o tema leitura, em produções de mestrado e doutorado, vinculadas aos programas de pós-graduação em Educação no país; no período de 2010 a 2015, apontou constatações relevantes. As problematizações dos estudos investigados abordam, principalmente, o trabalho docente com a leitura. Mesmo nas pesquisas que focalizavam o alunado, o trabalho docente acabou tendo destaque nas observações. Culminando numa responsabilização acentuada dos/as professores/as pela maioria dos problemas relacionados à aprendizagem da leitura (SILVA, 2017). Considera-se oportuno, então, que sejam realizadas mais pesquisas com foco nos/as discentes para a compreensão dos caminhos da aprendizagem da leitura.

\section{OBJETIVOS}

Considerando as questões já expostas, os objetivos desta pesquisa estão delineados da seguinte forma:

\section{I Objetivo geral}

Compreender as representações sociais de estudantes de correção de fluxo escolar sobre leitura, reconhecendo consensos, variabilidades e ancoragens que as consolidam.

\subsection{Objetivos Específicos}

- Reconhecer aspectos consensuais e variabilidades das representações sociais de estudantes de correção de fluxo sobre leitura.

- Comparar o comportamento dos/as educandos/as durante as situações de leitura nas aulas com o que foi revelado durante as entrevistas.

- Identificar possíveis transformações das representações dos/as discentes sobre leitura.

\section{PERCURSO METODOLÓGICO}

A metodologia empregada nesta pesquisa tem o estudo de caso como estratégia de investigação-ação, com abordagem qualitativa e modalidade etnográfica. Os instrumentos de produção de dados foram a observação participante, com registro em diário de campo, e a entrevista. Utilizou-se também à perspectiva quantitativa para mensurar determinados dados e assim obter elementos para o trabalho de interpretação. Desse modo, acredita-se que

$$
\begin{aligned}
& \text { a metodologia é apenas um caminho para lidar com as dualidades, um exercício } \\
& \text { de limites. Limites das possibilidades de investigar, das possibilidades do } \\
& \text { pesquisador, das do objeto, do contexto e da pesquisa. (...) } \\
& \text { Quantitativo/qualitativo não é uma dicotomia, mas sim uma parte das tensões } \\
& \text { constantes que e preciso aquilatar. (ARRUDA, 2002a) }
\end{aligned}
$$

Nesta pesquisa, devido ao objeto de estudo e à opção teórica, foi dada preferência ao olhar etnográfico da pesquisa qualitativa. Mattos (2011) esclarece que a etnografia também é chamada de "observação participante, pesquisa interpretativa, pesquisa 
hermenêutica, dentre outras" (p. 5I). Trata-se do estudo do modo de vida de um grupo específico de pessoas que se relacionam, com o intuito de "descrever os sistemas de significados culturais dos sujeitos estudados com base em sua ótica e em seu universo referencial” (ANDRÉ, 2012, p.45). Como nossa pesquisa tem o intuito de acessar as representações sociais de leitura entre um grupo particular de estudantes a partir da análise de discurso e considerando as interações sociais de modo holístico, é relevante mencionar que tais características se encaixam na chamada microanálise etnográfica. No referido instrumento da etnografia há uma atenção com o intuito das pessoas ao ter certos comportamentos e o que eles significam. Para isso

\footnotetext{
a microanálise etnográfica leva em consideração não somente a comunicação ou interação imediata da cena, como também a relação entre esta interação e o contexto social maior, a sociedade onde este contexto se insere". (MATTOS, 2011, p. 56)
}

Para identificação de possíveis transformações nas representações sociais do grupo foi preciso que a investigação tivesse caráter longitudinal, sendo desenvolvida ao longo do ano letivo. Sobre a pertinência e benefícios do estudo longitudinal, Velho (2008) destaca o fato de que uma vivência investigativa no decorrer de um tempo razoavelmente longo favorece o acesso a aspectos não explícitos, que requerem um trabalho pormenorizado e aprofundado de análise e empatia. Nesta pesquisa optou-se por um estudo de caso descrito por meio de uma microanálise. Para Yin (2015), o estudo de caso é o método mais adequado para questões do tipo "como?" e "por quê?", que envolvem um fenômeno social contemporâneo complexo. Conforme George e Bennett (2004), pesquisadores/as de estudos de caso estão empenhados/as em compreender as condições específicas nas quais os resultados ocorrem e o mecanismos por meio dos quais acontecem, e não em descobrir a frequência com que aparecem essas condições e resultados. Optou-se por realizar a o estudo com a turma na qual a pesquisadora atuou na docência no ano de 2017. A intenção foi acompanhar com maior proximidade as falas e comportamentos espontâneos dos/as estudantes relacionados à leitura e ter maior facilidade no contato com os pais/responsáveis para obtenção da autorização para a realização da pesquisa e para conversarmos em diferentes períodos do ano letivo sobre o desempenho escolar das crianças e suas relações com o ato de ler. A seleção do caso com algum conhecimento preliminar do/a pesquisador/a é apontado como favorável por George e Bennett (2004), possibilitando o desenvolvimento de estudos mais consistentes. $\mathrm{O}$ aspecto da proximidade com o grupo participante também favorece o acesso às informações pretendidas nos objetivos elencados para essa investigação. Segundo Yin (2005), as condições de aproximação com os dados interfere diretamente no potencial do estudo de caso, pois para o esclarecimento das questões de pesquisa é preciso acessibilidade às informações necessárias para análise. Outra vantagem é a possibilidade de acompanhamento do processo de transformações das representações sociais sobre leitura ao longo do ano letivo.

Para o alcance dos objetivos a pesquisa de campo ocorreu em três etapas. A primeira foi voltada para coleta de dados entre os/as estudantes e ocorreu no primeiro bimestre do ano letivo. Para isso foi utilizada a entrevista semiestruturada, que ser considerada pertinente devido à possibilidade "oferece todas as perspectivas possíveis para que o informante alcance a liberdade e a espontaneidade necessárias, enriquecendo a investigação" (TRIVIÑOS, 1987, p. 146) - especialmente por se tratar de uma pesquisa envolvendo crianças. As entrevistas foram realizadas individualmente. A segunda etapa 
correspondeu à realização de observação participante, que segundo Lakatos e Marconi (2003) auxilia o/a pesquisador/a na identificação e aquisição de elementos que comprovem as intenções que guiam o comportamento dos sujeitos sem que tenham essa percepção. Nesse caso, observou-se o comportamento dos/as estudantes durante as aulas, comparando suas atitudes nas situações de leitura com as falas das entrevistas. Os registros foram realizados num diário de campo. A pertinência da observação participante em estudos de representações sociais é justificada por Arruda (2015) por possibilitar o acompanhamento da etapa de construção do processo de elaboração - e no caso deste estudo também de transformações - das representações. Assim, como bem exemplifica a autora, o/a pesquisador/a acompanha “(...) o filme em movimento e não fotograma a fotograma" (ARRUDA, 2015, p. 12I). A terceira etapa da coleta de dados consistiu numa nova entrevista semiestruturada com os/as estudantes ao final do ano letivo para identificação de possíveis transformações nas representações sociais do grupo sobre a leitura. $\mathrm{O}$ desenho metodológico desta pesquisa ficou configurado da seguinte maneira:

Quadro I - Desenho metodológico da pesquisa

\begin{tabular}{|c|c|c|c|c|}
\hline \multirow[b]{2}{*}{ Etapas } & \multirow[b]{2}{*}{ Objetivos } & \multicolumn{2}{|c|}{ Procedimentos } & \multirow[b]{2}{*}{ Sujeitos } \\
\hline & & Coleta & Análise & \\
\hline $\mathbf{I}^{\mathrm{a}}$ & $\begin{array}{l}\text { Reconhecer } \\
\text { consensuais e variabilidades } \\
\text { das representações sociais de } \\
\text { leitura entre estudantes de } \\
\text { correção de fluxo. }\end{array}$ & $\begin{array}{c}\text { Entrevista } \\
\text { semiestruturada }\end{array}$ & \multirow{3}{*}{$\begin{array}{l}\text { Análise } \\
\text { de } \\
\text { Conteúdo }\end{array}$} & \multirow{3}{*}{$\begin{array}{l}\text { Oito } \\
\text { estudantes que } \\
\text { compõem uma } \\
\text { turma de } \\
\text { correção de } \\
\text { fluxo. }\end{array}$} \\
\hline $2^{\underline{a}}$ & $\begin{array}{l}\text { Comparar o comportamento } \\
\text { dos/as educandos/as durante } \\
\text { as situações de leitura com o } \\
\text { que foi revelado durante as } \\
\text { entrevistas. }\end{array}$ & $\begin{array}{l}\text { Observação } \\
\text { participante }\end{array}$ & & \\
\hline $3^{\mathrm{a}}$ & $\begin{array}{lr}\text { Identificar } & \text { possíveis } \\
\text { transformações } & \text { nas } \\
\text { representações sociais dos/as } \\
\text { discentes sobre leitura. }\end{array}$ & $\begin{array}{c}\text { Entrevista } \\
\text { semiestruturada }\end{array}$ & & \\
\hline
\end{tabular}

Fonte: Dos/as autores/as.

A primeira entrevista teve o intuito de alcançar o objetivo específico de reconhecer aspectos consensuais e variabilidades das representações sociais de leitura em estudantes de correção de fluxo no início do ano letivo. A observação participante buscou comparar o comportamento dos/as educandos/as durante os momentos de leitura com o que foi revelado durante as entrevistas. A segunda entrevista contemplou o objetivo específico de identificar prováveis mudanças nas representações sociais dos/as estudantes sobre leitura.

\section{I Caracterização do grupo participante do estudo}

Participaram do estudo oito estudantes (uma menina e sete meninos), com idade de II e I2 anos, matriculados/as na turma do Se Liga - programa de correção de fluxo escolar criado pelo Instituto Ayrton Senna e adotado como política pública pela Rede Municipal 
de Ensino do Recife -, no turno matutino, na Escola Municipal Presbítero José Bezerra. A turma é formada por discentes em situação de distorção idade-série, que deixaram suas turmas regulares de origem para serem alfabetizados/as no programa de correção de fluxo. O quadro a seguir retrata o perfil geral do grupo investigado. Foram utilizados nomes fictícios para preservação da identidade dos/as participantes.

Quadro 2-Caracterização geral da turma

\begin{tabular}{|c|c|c|c|c|c|c|c|}
\hline $\begin{array}{l}\text { Estudant } \\
\mathrm{e}\end{array}$ & $\begin{array}{c}\text { Idad } \\
\mathrm{e}\end{array}$ & $\begin{array}{l}\text { Turm } \\
\text { a de } \\
\text { orige } \\
\text { m }\end{array}$ & $\begin{array}{c}\text { Tempo } \\
\text { na } \\
\text { Educação } \\
\text { Infantil }\end{array}$ & $\begin{array}{l}\text { Tempo no } \\
\text { Ensino } \\
\text { Fundamen } \\
\text { tal }\end{array}$ & $\begin{array}{c}\text { Tempo } \\
\text { em } \\
\text { atividade } \\
\text { s extras }\end{array}$ & $\begin{array}{c}\mathrm{N}^{\circ} \mathrm{de} \\
\text { reprovaçõe } \\
\mathrm{s}\end{array}$ & $\begin{array}{c}\mathrm{N}^{\circ} \text { de } \\
\text { desistência } \\
s\end{array}$ \\
\hline Danilo & 12 & $4^{\circ}$ ano & 2 anos & 4 anos & 2 anos & I & $* * *$ \\
\hline Eduardo & 12 & $3^{\circ}$ ano & 4 anos & 4 anos & I ano & 2 & $* * *$ \\
\hline Gabriel & I2 & $3^{\circ}$ ano & 5 anos & 4 anos & $* * *$ & 2 & $* * *$ \\
\hline Jamerson & II & $4^{-}$ano & 4 anos & 4 anos & I ano & I & $* * *$ \\
\hline José & 12 & $4^{-}$ano & 4 anos & 5 anos & 3 anos & 2 & I \\
\hline Marina & II & $2^{\circ}$ ano & 2 anos & 2 anos & I ano & 2 & I \\
\hline Paulo & 12 & $3^{\circ}$ ano & $* * *$ & 5 anos & I ano & 2 & I \\
\hline Raul & 12 & $2^{\circ}$ ano & I & 3 anos & $* * *$ & I & $\mathrm{I}$ \\
\hline
\end{tabular}

Fonte: Dos/as autores/as.

Considerou-se ser relevante o conhecimento do histórico escolar dos/as participantes da pesquisa uma vez que suas atitudes diante de situações de leitura estão relacionadas às vivências educacionais anteriores. Os dados expostos no quadro revelam que um longo período de tempo frequentando uma mesma instituição escolar não assegurou a aprendizagem da leitura. Situação evidente e grave especialmente nos casos dos/as educandos/as com permanência de seis e sete anos em contato com a equipe pedagógica de uma mesma escola sem a obtenção de avanços na apropriação do sistema de escrita alfabética. Solé (1998) defende a ideia de que o ensino da leitura deve der considerado uma questão de equipe para evitar a descontinuidade e/ou a ausência de conexão nesse processo.

\subsection{Procedimentos de Análise de Dados}

Para uma aproximação das representações sociais dos educandos foi adotada a análise de conteúdo. Essa abordagem metodológica tem o objetivo de

explicar e sistematizar o conteúdo da mensagem e o significado desse conteúdo, por meio de deduções lógicas e justificadas, tendo como referência sua origem (quem emitiu) e o contexto da mensagem ou os efeitos dessa mensagem. (OLIVEIRA et al., 2003, p. 3-4)

Esse tipo de análise possibilita a investigação de variáveis inferidas a partir dos indicadores explícitos e sua categorização. A análise foi realizada em três etapas: préanálise, exploração do material e tratamento dos resultados (BARDIN, 1979). Na préanálise sistematizou-se os dados obtidos durante as entrevistas e observações, bem como realizamos leituras flutuantes, isto é, uma leitura inicial de reconhecimento das ideias expostas. Essa etapa teve por objetivo identificar os temas que se repetiam com 
maior frequência a fim de categorizá-los para posterior interpretação. A exploração das informações consistiu na leitura detalhada do material e separação do mesmo em categorias seguindo o critério: apresentação de características comuns. Segundo Bardin (1979), a categorização é um modo de organização presente na maioria dos estudos qualitativos, visto que sintetiza uma forma de pensamento de determinado momento acerca de temas específicos. Após o estabelecimento das categorias passou-se para o tratamento dos resultados, momento de inferências e interpretações referente às informações obtidas sobre o tema estudado.

\subsection{Análise e discussão dos resultados: Representações sociais dos/as estudantes sobre leitura}

A partir da etapa de exploração do material foram definidas as seguintes categorias de análise para as representações de leitura do grupo de estudantes pesquisado: concepções ancoradas em aspectos positivos, concepções ancoradas em aspectos negativos, concepções ancoradas na escolarização e concepções ancoradas no letramento.

\subsection{Concepções ancoradas em aspectos positivos sobre a leitura}

No início do ano letivo, ao refletir acerca do ato de ler, seis dos oito estudantes apontaram em suas falas, durante a primeira entrevista, representações ancoradas em ideias positivas relacionadas à leitura: Danilo, Eduardo, Gabriel, José, Marina e Raul. Os estudantes Jamerson e Paulo foram os que não se referiram de modo positivo à leitura. Emergiram nos discursos do grupo as afirmações subsequentes: (I) Ler é bom, (I) é legal, (I) é importante, (I) é saber um bocado de coisas, (I) nos faz aprender, (I) é bom pra quem sabe, (I) por um lado é uma coisa boa. Foi considerado o número de respostas dadas e não de estudantes, nesta e nas demais respostas em análise, bem como mantivemos o vocabulário original do grupo. As duas últimas falas, apesar de positivas, revelam um relativismo ligado à condição de saber ler:

\footnotetext{
É bom pra quem sabe. Pode ler livro, caderno... Mas, é difícil. (Eduardo, I2 anos, $3^{\text {o }}$ ano)

Por um lado é uma coisa boa. Mas, tem hora que dá medo (...). (Raul, 12 anos, $2^{\circ}$ ano)
}

Ao tentar explicar o que é leitura, os alunos Eduardo (I2 anos) e Raul (I2 anos) evidenciam que estão em fase de (re)elaboração de representações. Apesar de perceberem que se trata de algo bom e necessário para as pessoas em volta, por não serem leitores, isso não basta para que eles também representem o ato de ler como totalmente positivo. Destarte, expõem o desconforto que sentem em situações de leitura como justificativa para o relativismo. De acordo com Moscovici (2015), é nesse contexto de reflexões e divergência de ideias, na procura por respostas, que deve acontecer as investigações das representações sociais e não na conjuntura de como a pessoa age, ou seja, exatamente na ocasião em que ela busca entender e não comportar-se. No final do ano as percepções positivas emergiram de forma mais efetiva e favorável por meio de falas mais específicas e categóricas, refletindo o sentimento de contentamento por aprender a ler: (I) Ler é um tipo de alegria porque você sabe, (I) é felicidade, (I) é sabedoria, (I) é feito música, (I) é a melhor coisa da vida, (I) com a leitura você pode fazer tudo, (I) é se dar bem, (I) é uma coisa muito boa pra pessoa, (I) não dá o mesmo medo do começo, (I) te deixa mais 
esperta e contente, (I) é fácil se você quiser, (I) é incrível, (I) é descobrir coisas, (2) é bom, (2) é aprender, (2) gosto. Novamente a relatividade aparece na fala do aluno Raul (I2 anos, $2^{\circ}$ ano), que explicou:

Ler é fácil se você quiser. Se você não quiser, você não vai conseguir ler. Por exemplo, a senhora de vez em quando diz: - Você, se você quiser fazer uma festa, você vai fazer uma festa. Se você não quiser, você não vai fazer uma festa, porque você não tá com vontade, com inspiração.

Em seu discurso, o estudante cita uma fala da professora para justificar sua ideia sobre a importância do desejo e da motivação no processo de aprendizagem da leitura. $\mathrm{O}$ mesmo aluno fez uso de comparações para explicar o que é leitura:

Ler é tipo uma alegria porque você sabe. É uma felicidade pra quem não sabia ainda. Por exemplo, eu. Ler é feito uma música: a gente escuta, escuta, escuta... Mas, nunca acaba. (Raul, 12 anos, $2^{\circ}$ ano)

Para o educando Raul o caráter de infinitude de uma canção assemelha-se ao ato de ler, sendo o ponto de intersecção que o fez elaborar uma metáfora. Já a leitura enquanto alegria é justificada pela sensação de contentamento originada pela capacidade recém adquirida de ler. Por meio de metáforas foi exposto o processo de objetivação, que organiza o pensamento e transforma um conceito numa imagem facilmente acessada, colaborando com o compartilhamento da ideia acerca do objeto nas práticas comunicativas (CASTRO, C.; CASTRO, M., 2018). De modo simultâneo, a ideia sobre a ação de ler é incorporada numa teia de padronizações familiares para a elaboração de um significado, processo chamado por Moscovici (2015) de ancoragem. Ao comparar a leitura à música o estudante simplifica o conceito de leitura, ação chamada por Jodelet (200I) de construção seletiva e que integra o processo de objetivação, ao mesmo tempo em que expõe a etapa de naturalização (JODELET, 20oI) da objetivação ao expressar um conceito por meio da metáfora. Já o processo de ancoragem, que está ligado à utilidade conferida à representação (JODELET, 200I), é percebida na justificativa ligada à infinitude do ato de ler. A leitura é então representada como algo infindável. Segundo Ricouer (2005), a metáfora é uma forma pela qual o discurso evidencia o poder que determinadas ficções possuem de reformular descrições da realidade. Nesse sentido, a metáfora constitui-se como modo de produção de significado. Os esquemas a seguir ilustram de forma sintética as elaborações metafóricas feita pelo estudante Raul:

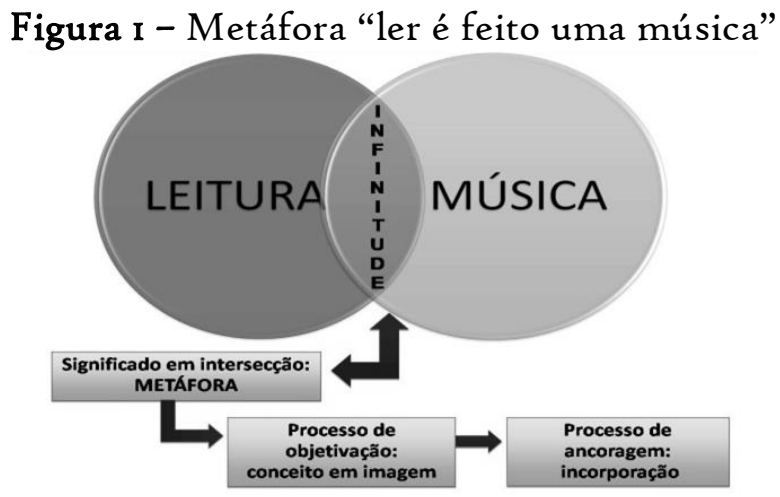

Fonte: Elaborada pelos/as autores/as, a partir Castro, C. e Castro, M. (2018). 
Figura 2 - Metáforas "ler é tipo uma alegria" e "é uma felicidade"

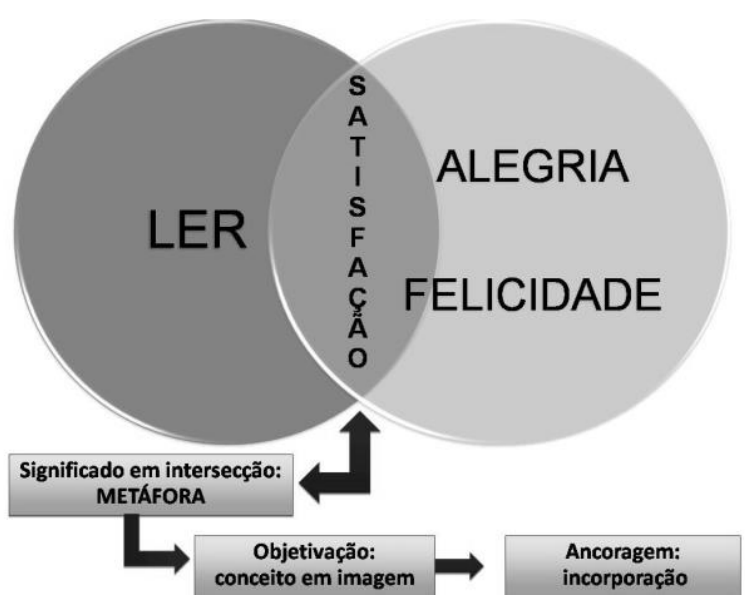

Fonte: Elaborada pelos/as autores/as, a partir Castro, C. e Castro, M. (2018).

Os estudantes Danilo e Paulo, ao afirmarem que "ler é aprender", e Gabriel ao dizer que "ler é sabedoria", também utilizam conexões metafóricas para expressarem o entendimento sobre o objeto representado (CASTRO, C.; CASTRO, M., 2018). Nesse caso, a partir do pensamento de que ler é compreender informações de um texto, que aprender é passar a ter conhecimento sobre algo, e que sabedoria é o conjunto de conhecimentos, percebe-se como ponto interseccional a noção de assimilação de saberes. O esquema subsequente mostra as construções de metáforas:

Figura 3 - Metáforas "ler é aprender" e "ler é sabedoria"

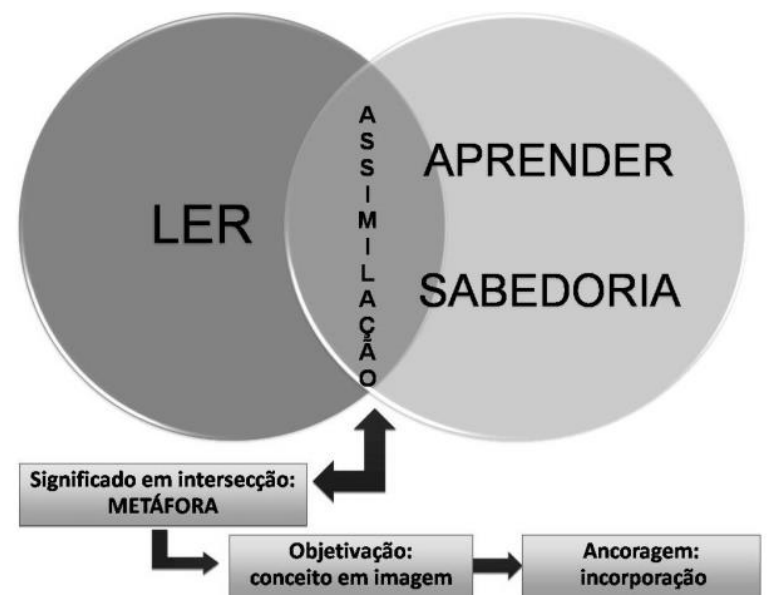

Fonte: Elaborada pelos/as autores/as, a partir Castro, C. e Castro, M. (2018)

Considera-se importante identificar as falas de cada estudante nos quadros dos indicadores das categorias para que fiquem mais claras as posteriores análises de 
transformações e manutenções das representações das crianças, bem como as articulações com os perfis dos participantes e suas outras falas citadas ao longo do trabalho. Nessa perspectiva, destaca-se que os conteúdos das representações sociais são integrantes de um repertório simbólico cujas fontes não podem ser desconsideradas nos momentos de análise dos discursos dos atores sociais em questão, sendo preciso compreender que, inexoravelmente, cada pessoa constrói sua própria opinião e forma uma visão pessoal da realidade, sem que isso signifique que seja um processo de elaboração individual e idiossincrático (UMAÑA, 2002).

Quadro 3-Concepções ancoradas em aspectos positivos sobre o ato de ler

\begin{tabular}{|c|c|c|}
\hline Indicadores do início do ano & Indicadores do final do ano & Estudantes \\
\hline É legal. & $\begin{array}{l}\text { É aprender. É se dar bem. É uma coisa } \\
\text { muito boa pra pessoa. }\end{array}$ & Danilo \\
\hline É bom pra quem sabe. & É bom. Gosto. & Eduardo \\
\hline É bom. & $\begin{array}{l}\text { É sabedoria. É bom. É descobrir coisas. } \\
\text { É incrível. }\end{array}$ & Gabriel \\
\hline É saber um bocado de coisas. & $\begin{array}{l}\text { Não dá o mesmo medo do começo. } \\
\text { Gosto. }\end{array}$ & José \\
\hline É importante. & Te deixa mais esperta. & Marina \\
\hline$* * *$ & É aprender. & Paulo \\
\hline $\begin{array}{l}\text { Ler nos faz aprender. É bom por } \\
\text { um lado. }\end{array}$ & $\begin{array}{l}\text { É um tipo de alegria. É felicidade. É a } \\
\text { melhor coisa da vida. É fácil se você } \\
\text { quiser. Ler é feito música. }\end{array}$ & Raul \\
\hline
\end{tabular}

Fonte: Dos/as autores/as.

Dos/as oito estudantes participantes, sete avançaram para o nível alfabético. Apenas o aluno Jamerson não avançou. Por conta do excesso de ausências nas aulas precisou retornar à turma de origem - seguindo as normas do programa de correção de fluxo - no mês de setembro, pois não havia mais possibilidades de aceleração devido ao fato de já ter o número de faltas que resulta em retenção. Jamerson foi o único participante que não expôs falas positivas sobre o ato de ler durante as entrevistas. Ao longo das observações foi possível ter acesso a relatos importantes da professora da biblioteca, que revelam mudanças significativas nas ideias sobre leitura, que impactam nos comportamentos das crianças em relação ao ato de ler:

Marina esteve aqui (na biblioteca) tão feliz! Disse que a professora explicou que também podemos ler imagens. Então ela precisava pegar livros de imagens para ler. Falou: - Eu já sei o que é uma literatura com letras e com imagens. Posso ler com letras e com imagens. Minha professora ensinou como ler a capa... Tem o nome do autor. (Professora da biblioteca)

A partir dessa narrativa pôde-se compreender melhor uma atitude da aluna que chamou a atenção: Durante o recreio ela pediu para ir à biblioteca. $\mathrm{Na}$ volta para sala de aula colocou espontaneamente o livro que pegou emprestado no cantinho da leitura, junto às obras que compõe o acervo da turma. Sua ação foi valorizada com um agradecimento por compartilhar com o grupo uma indicação de leitura. Marina sorriu orgulhosa. No dia seguinte o aluno José agiu da mesma forma. Pegou um livro emprestado na biblioteca e pôs no cantinho da leitura. Ele também foi elogiado pela iniciativa e os colegas demonstraram interesse em ler o título sugerido. Os pedidos para ir à biblioteca 
tornaram-se cada vez mais frequentes. Fato que fez com que ficasse combinado que quem finalizasse as atividades poderia ir fazer empréstimos e devoluções de livros na biblioteca, ou realizar leituras no local. Percebe-se que a ideia de ser capaz de ler um livro de imagens proporcionou mudanças sobre a concepção de leitura, que se refletiram em atitudes de interesse pelo ato de ler. A atitude é uma das dimensões das representações sociais. As atitudes não revelam o conhecimento em si, mas uma relação de certeza e dúvida, confiança ou descrença relativa a tal conhecimento (MOSCOVICI, 2015). Sob essa ótica, ao analisar o senso comum não se deve confundir o conceito de atitude com o de representações sociais ou substituir um pelo outro. E sim considerar suas correlações e indissociabilidade. Nas situações de interação entre as crianças e o ato de ler aparentemente há uma relação binária entre a atitude e o objeto. Contudo, essa relação é tríade, pois também envolve a representação social que intervém nessa relação (MOSCOVICI, 2015).

\subsubsection{Concepções ancoradas em aspectos negativos sobre a leitura}

Muitas das percepções ancoradas em ideias negativas sobre o ato de ler foram expostas em afirmações relativas aos sentimentos que surgem em situações de leitura, como nas falas: (I) sinto pressão, (I) é ruim pra quem não sabe, (I) tem hora que dá medo, (2) dá vergonha, (3) dá medo, (3) é difícil, (2) é ruim, (3) fico nervoso/a. Novamente o relativismo apareceu nas falas dos mesmos garotos, Eduardo e Raul, que justificam o porquê ler é ruim e dá medo:

Ler é ruim pra quem não sabe. Eu fico nervoso porque não consigo ler. É ruim... (Eduardo, 12 anos, $3^{\circ}$ ano)

(...) Tem hora que dá medo, que é uma coisa que dá um frio na barriga. É difícil. Quando a gente não consegue juntar as letras dá um frio na barriga. (Raul, I2 anos, $2^{\circ}$ ano)

No quadro a seguir verifica-se que os/as seis estudantes que apontaram ideias ancoradas em aspectos positivos sobre a leitura também expressaram percepções ancoradas em percepções negativas sobre o ato de ler. Os educandos Jamerson e Paulo, que não apresentaram falas positivas sobre a leitura, expuseram concepções negativas sobre a questão. Jamerson referiu-se ao medo. Paulo, além do medo, citou o nervosismo e o fato de ser algo ruim.

Quadro 4-Concepções ancoradas em aspectos negativos sobre o ato de ler

\begin{tabular}{|c|c|}
\hline Indicadores & Estudantes \\
\hline Sinto pressão. & Danilo \\
\hline $\begin{array}{c}\text { É ruim pra quem não } \\
\text { sabe. }\end{array}$ & Eduardo \\
\hline Tem hora que dá medo. & Raul \\
\hline Fico com vergonha. & Gabriel, José \\
\hline É ruim. & José, Paulo \\
\hline Dá medo. & Danilo, Paulo, Jamerson \\
\hline É difícil. & Eduardo, Gabriel, Raul \\
\hline Fico nervoso/a. & Eduardo, Marina, Paulo \\
\hline
\end{tabular}

Fonte: Dos/as autores/as. 
De acordo Moscovici (2012), atribuir uma característica, ou um rótulo, a algo que não conhecemos bem é uma necessidade, pois se trata de uma maneira de dar um lugar a determinado objeto, dentro de um conjunto de conhecimentos já representados por determinado grupo. Quando se atribui um valor a um objeto, ou a uma pessoa, de modo positivo ou negativo, a base são os juízos de valores já estabelecidos. Desta forma, a classificação consiste no enquadramento de uma imagem anteriormente pensada, de um objeto ou pessoa a um determinado grupo. Tal ação é chamada por Moscovici (2015) de ancoragem. Segundo Arruda (2000), "as representações sociais não são apenas tributárias do passado, mas são passagem para o futuro: está se construindo hoje o acervo cognitivoafetivo com o qual se lidará amanhã (p.244)". No caso do grupo pesquisado, o fato de não estar alfabetizado numa faixa etária e numa série de origem onde o esperado é que já se saiba ler, os momentos de desconforto relacionados à leitura foram/são (e serão, caso não haja mudança quanto a isso) diários. Assim, concepções ancoradas em ideias negativas de leitura vão sendo construídas a partir das vivências pautadas no sentimento de não conseguir, de não saber, de não ser capaz; como podemos verificar nas falas a seguir sobre o ano anterior:

No ano passado eu não conseguia fazer as tarefas porque tinha que ler. Às vezes a professora pedia pra eu ler o que tava no quadro. Aí eu me escondia (o aluno demonstrou como fazia, abaixando-se sob a mesa). (Gabriel, I2 anos, $3^{\circ}$ ano)

A hora que eu menos gostava era a hora de ler. (Raul, 12 anos, $2_{2}^{\circ}$ ano)

Eu não gostava de ler nem de fazer tarefa. (Eduardo, 12 anos, $3^{\circ}$ ano)

Eu repeti de ano porque eu não sabia ler. (Danilo, $\mathrm{I2}$ anos, $4^{ }$ano)

A partir dessa reflexão percebe-se que determinadas percepções ancoradas em ideais positivas de leitura (apresentadas no item anterior) são elaboradas a partir da necessidade de se saber ler para evitar desconfortos (medo, nervosismo, vergonha) e não no prazer que pode proporcionar ao leitor, como é verificado nas falas abaixo:

\footnotetext{
Minha mãe pede pra eu ler o nome do ônibus e eu não sei... É bom saber ler pra ler as coisas na rua, nos livros... (Gabriel, 12 anos, $3^{\circ}$ ano)

Se sabe ler, você não precisa ficar pedindo pra alguém ler. (José, I2 anos, $4^{\circ}$ ano)

É melhor saber ler... Pra ler o quadro, o livro, qualquer coisa! (Eduardo, I2 anos, $3^{\circ}$ ano)
}

Durante a segunda entrevista, realizada no final do ano letivo, não foram identificados indicadores negativos sobre o ato de ler. Fato que indica que ocorreram transformações nas representações de leitura do grupo investigado. Nesse sentido, o aluno Raul ( 12 anos, $2^{-}$ano) falou em nome da turma após a leitura de um texto longo de forma compartilhada:

A gente superou o medo de ler. (A afirmação foi confirmada pelo balançar de cabeças e sorrisos do grupo.)

É importante destacar que a atitude do estudante de partilhar seu pensamento sobre a mudança de concepção acerca da leitura, concebendo-o enquanto ideia grupal, revela o caráter social das representações. Conforme Moscovici (2015) "nós formamos novas representações a partir das anteriores, ou contra elas" (p. 319). Arruda (2000) complementa essa ideia ao explicar que 


\begin{abstract}
Arepresentação social, processo socialmente elaborado e compartilhado com o objetivo de dar sentido à novidade, estabelecer comunicação, dominar o meio, se apoia num projeto e num passado que não são somente individuais, mas coletivos; e não é só passado, mas é memória e imaginário, herança e esperança, como diria Baczko (1991). (p.243)
\end{abstract}

No caso em questão, os sujeitos pesquisados expressaram a percepção de que as ideias negativas sobre a leitura foram suplantadas, implicando na construção de um novo olhar relativo à leitura. Essa elaboração parte concomitantemente de aspectos préexistentes e de expectativas relativas ao objeto representado (ARRUDA, 200o).

\title{
3.3.3 Concepções de leitura ancoradas na escolarização
}

Dentre as falas sobre leitura, todas as crianças apresentaram percepções atreladas às situações escolares, afinal, é nesse ambiente em que são mais expostas direta e sistematicamente às práticas de leitura. No início do ano foram observados os seguintes indicadores: (I) Estudar, (I) juntar palavras, (I) importante para escrever, (I) ler o quadro, (I) se esforçar nas tarefas, (I) coisa que nos ajuda a escrever certo, (2) juntar letras, (4) ler para passar de ano, (5) ler livros e cadernos.

Ao final do ano as falas foram: (I) Ler para escrever livros, (I) estudar, (I) explicar o que é o nome, (I) comer os livros para aprender mais, (I) pegar o livro e ler até o final, (3) saber escrever. O quadro a seguir sistematiza os indicadores que emergiram de acordo com cada estudante.

Quadro 5 - Concepções de leitura ancoradas na escolarização

\begin{tabular}{|c|c|c|}
\hline Indicadores do início do ano & Indicadores do final do ano & Estudantes \\
\hline $\begin{array}{c}\text { Ler é estudar. Ler para passar de ano. } \\
\text { Ler é se esforçar nas tarefas. }\end{array}$ & Ler é para escrever livros. & Danilo \\
\hline $\begin{array}{c}\text { É ler o quadro. Ler para passar de ano. } \\
\text { Ler livros e cadernos. }\end{array}$ & $\begin{array}{c}\text { É uma coisa que ajuda a gente a } \\
\text { escrever certo. }\end{array}$ & Eduardo \\
\hline $\begin{array}{c}\text { Ler é juntar palavras. Ler livros e } \\
\text { cadernos. }\end{array}$ & $\begin{array}{c}\text { Ler é pegar o livro, começar do } \\
\text { começo até o final. }\end{array}$ & Gabriel \\
\hline $\begin{array}{c}\text { Importante para escrever. Ler é juntar } \\
\text { letras. }\end{array}$ & $\begin{array}{c}\text { Ler é estudar. Ler é saber escrever. } \\
\text { Ler livros e cadernos. }\end{array}$ & Marina \\
\hline É ler livros e cadernos. & Ler é explicar o que é o nome. & Jamerson \\
\hline $\begin{array}{c}\text { Ler para passar de ano. Ler livros e } \\
\text { cadernos. }\end{array}$ & $\begin{array}{c}\text { Ler é comer os livros para } \\
\text { aprender mais. }\end{array}$ & Paulo \\
\hline Ler é juntar as letras. & Raul \\
\hline
\end{tabular}

Fonte: Dos/as autores/as.

É imprescindível destacar que determinados indicadores relacionados tanto à escolarização quanto ao letramento (descritos no item a seguir) estão conectados com outras concepções de leitura, por exemplo, "passar de ano" também se enquadra como uma concepção positiva, assim como "juntar letras" pode se configurar como uma concepção negativa na medida em que provoca medo ou vergonha em quem não sabe ler. 
Contudo, optou-se por diferenciar tais categorias para abranger de modo específico as interferências das práticas escolares de alfabetização e letramento na construção das representações do grupo pesquisado.

O diálogo que será apresentado a seguir demonstra a concatenação entre as representações sobre leitura e autoidentificação. Trata-se de uma situação na qual Gabriel ( 12 anos, $3^{-}$ano) e Eduardo ( 12 anos, $3^{-}$ano) estavam fazendo uma leitura em dupla. Gabriel, que já estava no nível alfabético, ajudava o colega que estava no nível silábicoalfabético:

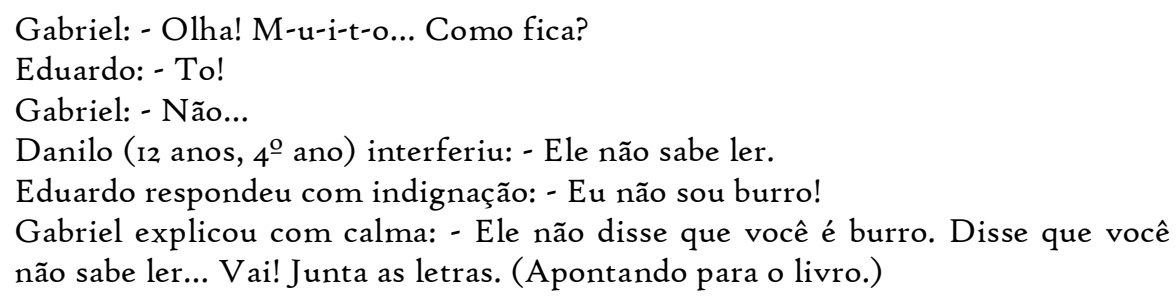

Esse tipo de conversação entre os estudantes expõe como ocorre o processo de (re)construção de novas representações sociais, visto que estas são construídas "através de influências recíprocas, através de negociações implícitas no curso de conversações, onde as pessoas se orientam para modelos simbólicos, imagens e valores compartilhados específicos” (MOSCOVICI, 2015, p. 208). No diálogo exposto, o estudante Gabriel, que auxilia Eduardo na leitura, tenta convencê-lo de que ler é juntar letras. Por isso vai soletrando no intuito de ajudá-lo a decodificar a palavra. Ao ouvir a leitura incorreta do colega, Danilo logo deduz que ele não sabe ler. Ao responder que "não é burro", Eduardo $\mathrm{fez}$ emergir sua representação negativa sobre pessoas que não sabem ler. Por estar em processo de alfabetização, lendo palavras familiares, crê que não se enquadra nessa classificação. Verifica-se que ele não se identifica como alguém analfabeto, comumente chamado de "burro" na escola. É importante destacar que o aluno Eduardo durante a primeira entrevista realizada no início do ano letivo informou que não sabia ler. Com o decorrer do tempo, ao participar de atividades alfabetizadoras, o estudante não mais se identificava como um não leitor.

Sobre essa questão da autoidentificação Berger e Luckmann (2004) explicam que o sujeito mantém sua autoidentificação mediante a confirmação do meio numa relação significativa. Assim, uma interrupção no diálogo significativo com os intercessores dos suportes de aceitabilidade possibilita mudanças nas realidades subjetivas em discussão. Diante do tom de revolta de Eduardo ao afirmar que não é burro, Gabriel apresenta sua interpretação sobre a fala de Danilo, confirmando que ele não chamou o colega de burro. Essa situação vivida em sala de aula demonstra que

\footnotetext{
ao mesmo tempo que o aparelho de conversa mantém continuamente a realidade, também continuamente a modifica. Certos pontos são abandonados e outros acrescentados, enfraquecendo alguns setores daquilo que ainda é considerado como evidente e reforçando outros. (BERGER e LUCKMANN, 2004, p. 203)
}

Destarte, a conversa delineia de modo firme questões que eram percebidas de forma imprecisa e pouco nítidas (BERGER; LUCKMANN, 2004). Daí a importância $\mathrm{dos} /$ as profissionais que atuam na escola estarem atentos/as aos momentos de conversas entre os discentes para buscarem compreender seus pontos de vista, suas relações com os saberes em estudo, suas representações etc., para assim poderem planejar intervenções didáticas específicas, eficientes e coerentes com a realidade vivenciada pelo alunado. No 
curto diálogo entre os educandos é possível identificar ideias atreladas às concepções de leitura e de não leitores, apresentando o caráter dinâmico das representações sociais, que para Moscovici (2015) se revelam como um entrelaçado de ideias, símbolos e metáforas com conexões de diferentes níveis, tendo como principal transmissor o discurso. Segundo o autor, as representações norteiam pensamentos e ações, pois são construídas com duas finalidades: ação e avaliação. Nessa perspectiva, "o que as pessoas pensam determina como elas pensam" (MOSCOVICI, 2015, p. 2II). O estudante Raul, novamente, fez uso de uma relação metafórica para explicar o que é leitura, condensando o significado do objeto na ideia de congruência entre a prática de ler e de alimentar-se:

Ler é comer os livros para aprender mais. (Raul, 12 anos, $2^{\circ}$ ano)

Nesse caso o consumo de alimentos, fundamental para a absorção de nutrientes, foi comparado à assimilação de novos saberes pela ação da leitura, tendo a noção de "aquisição" como ponto de confluência dos significados. O esquema a seguir apresenta a metáfora elaborada pelo aluno:

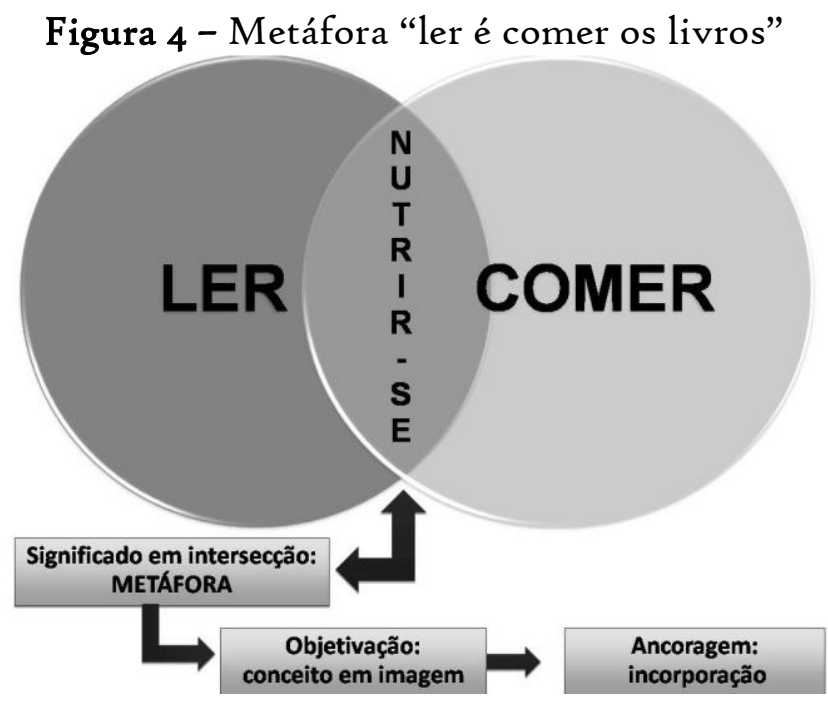

Fonte: Elaborada pelos/as autores/as, a partir Castro, C. e Castro, M. (2018).

No que tange às representações de leitura atreladas à escolarização percebemos que houve transformações das ideias no intervalo de tempo entre a primeira e a segunda entrevista. No início e no final do ano todos citaram aspectos escolares. No entanto, na primeira entrevista emergiram afirmações mais "tradicionais": ler é juntar letras, ler para passar de ano, é ler livros e cadernos... Já na segunda entrevista a maioria das falas reportaram-se à leitura ligada à escrita autônoma, seguida da ideia de aprender e compreender as palavras. Atribui-se essas mudanças de pensamento ao fato do grupo ter participado ativamente de projetos didáticos que valorizavam a escrita estudantil enquanto ação de protagonismo dos discentes, uma vez que os momentos de escrita autônoma vivenciados pelos/as estudantes exigiam leitura e releitura dos textos produzidos. Percebe-se, então, que transformações nas representações podem ocorrer no cerne de uma mesma categoria, e não só no contexto de extinção ou substituição desta. Contudo, as transformações na referida categoria impactaram no fortalecimento das concepções positivas de leitura, que passaram a ser mais afetivas. As mudanças relativas às representações de leitura ligadas à escolarização estão concatenadas à contribuição para suplantação das visões negativas sobre o ato de ler, pois o grupo passou a conceber a leitura enquanto ferramenta imprescindível para êxito em situações significativas e contextualizadas de escrita na escola. 


\subsubsection{Concepções de leitura ancoradas no letramento}

No que se refere às ideias sobre o ato de ler atreladas às práticas de letramento, verificamos os seguintes indicadores no início do ano letivo citados por quatro participantes: (I) Importante para conseguir trabalho, (I) usar no trabalho, (I) ler placas, (2) ler nome de ônibus, (2) ler coisas na rua, (I) ler qualquer coisa, (I) não precisar pedir ajuda para alguém ler. Ao final do ano três participantes se referiram ao letramento: (I) ler contratos, (I) ler permite fazer escolhas de coisas, (I) ler para ganhar um trabalho, (3) ler nomes nos ônibus. O quadro a seguir retrata a sistematização das falas nas duas etapas de entrevistas.

Quadro 6 - Concepções de leitura ancoradas no letramento

\begin{tabular}{|c|c|c|}
\hline Indicadores no início do ano letivo & Indicadores no final do ano letivo & Estudantes \\
\hline $\begin{array}{c}\text { Importante para conseguir trabalho, usar no } \\
\text { trabalho, ler placas, ler nome de ônibus, coisas } \\
\text { na rua. }\end{array}$ & $\begin{array}{c}\text { Ler nomes nos ônibus. Ler contratos. } \\
\text { Ler permite fazer escolhas de coisas. }\end{array}$ & Danilo \\
\hline Ler coisas na rua, nome do ônibus. & $* * *$ & Gabriel \\
\hline Ler qualquer coisa. & $* * *$ & José \\
\hline Não precisar pedir ajuda para alguém ler. & Ler para ganhar um trabalho. Ler \\
& nomes nos ônibus. & Jamerson \\
\hline$* * *$ & Ler nomes dos ônibus. & Marina \\
\hline
\end{tabular}

Fonte: Dos/as autores/as.

Tem-se como exemplo da exteriorização da concepção de leitura ligada ao letramento um diálogo que ocorreu em sala de aula, quando o aluno Danilo (I2 anos, $4^{\mathrm{o}}$ ano) pede que o colega Gabriel ( 12 anos, $3^{\circ}$ ano) confirme que ele sabe ler:

Danilo: - Eu sei ler! Eu não escrevi tudo certo no whatsapp, não foi?

Gabriel: - Foi.

(Danilo sorriu com expressão de orgulho e satisfação pela confirmação de Gabriel)

Verifica-se na fala de Danilo a ideia de que escrever corretamente é sinal de que se sabe ler. Pensamento que também apareceu nas afirmações dele e de colegas durante as entrevistas, especialmente na segunda, nas falas ligadas à escolarização. Novamente a conversa, considerada por Berger e Luckmann (2004) como "o veículo mais importante de conservação da realidade" (p. 202), demonstra o quão a comunicação verbal constantemente conserva, modifica e recompõe a realidade subjetiva.

\subsubsection{Distribuição do grupo quanto às categorias referentes às representações de leitura}

A partir da análise dos dados da primeira entrevista, que foi realizada no período de início das aulas da turma pesquisada no Programa Se Liga, verificou-se que quatro 
estudantes, Danilo, Eduardo, Gabriel e José, contemplaram em suas falas as quatro categorias que emergiram sobre a leitura: concepções positivas, concepções negativas, concepções atreladas à escolarização e concepções ligadas ao letramento. Dois estudantes, Marina e Raul, abarcaram três categorias: concepções positivas, concepções negativas, concepções atreladas à escolarização. Os outros dois discentes, Jamerson e Paulo, tiveram suas falas enquadradas em duas categorias: concepções negativas, concepções atreladas à escolarização. Com a averiguação da segunda entrevista, devido à ausência de falas negativas sobre a leitura, nenhum/a estudante evocou quatro categorias.

Foi constatado que ao final do ano apenas um aluno, Danilo, e uma aluna, Marina, se enquadravam em três categorias: concepções positivas, concepções atreladas à escolarização e concepções ligadas ao letramento. Nesse caso, Marina teve ideias atreladas ao letramento acrescentadas à sua fala e Danilo manteve as outras três categorias identificadas inicialmente. Cinco educandos, Eduardo, Gabriel, José, Paulo e Raul, abrangeram duas categorias em comum: concepções positivas e concepções atreladas à escolarização. Nessa situação, Paulo demonstrou ter passado a ter representações positivas acerca da leitura e Raul excluiu as concepções negativas e manteve as demais categorias. Já Eduardo, Gabriel e José, cujas falas se enquadravam em quatro categorias, evocaram apenas duas na segunda entrevista.

$\mathrm{O}$ aluno Jamerson combinou duas categorias diferentes dos demais: concepções atreladas à escolarização e concepções ligadas ao letramento. Dessa forma Jamerson foi o único que não evocou representações ancoradas em ideias positivas sobre o ato de ler. Cabe relembrar que o estudante retornou à turma de origem antes do fim do ano letivo devido ao excesso de faltas que o impedia de acelerar nos estudos. Sobre a diversidade de combinações de ancoragens identificadas, especialmente no que concerne às crianças que apresentaram concepções ancoradas em aspectos positivos e concomitantemente concepções ancoradas em aspectos negativos, constata-se a coexistência de formas de pensamentos e representações discordantes num mesmo sujeito. Fato já comentado por Moscovici (2015) como algo relacionado ao caráter polifásico do conhecimento. Assim, as pessoas usam diferentes representações - inclusive contraditórias - de acordo com as circunstâncias. No caso das falas dos/as estudantes, verificou-se de modo geral que a leitura é considerada como algo bom e importante, mas que ao mesmo tempo provoca medo e é concebida como "ruim" no contexto em que o indivíduo não está alfabetizado.

O quadro a seguir retrata a composição das categorias representacionais de leitura por estudante de acordo com as ancoragens:

Quadro I - Distribuição por estudante quanto às categorias de representações

Estudantes

Danilo
CAL

\section{Categorias no início do ano}

CAAP,

CAAP,

CAL

Gabriel

José
CAAP, CAAN, CAE,

CAL

CAL

CAAP, CAAN, CAE,
Categorias no final do ano

CAAP, CAE, CAL

CAAP, CAE

CAAP, CAE

CAAP, CAE 


$\begin{array}{cll}\text { Jamerson } & \text { CAAN, CAE } & \text { CAE, CAL } \\ \text { Marina } & \text { CAAP, CAAN, CAE } & \text { CAAP, CAE, CAL } \\ \text { Paulo } & \text { CAAN, CAE } & \text { CAAP, CAE } \\ \text { Raul } & \text { CAAP, CAAN, CAE } & \text { CAAP, CAE }\end{array}$

Legenda: Concepções Ancoradas em Aspectos Positivos (CAAP), Concepções Ancoradas em Aspectos Negativos (CAAN), Concepções Ancoradas na Escolarização (CAE), Concepções Ancoradas no Letramento (CAL).

Fonte: Dos/as autores/as.

Já o quadro seguinte expõe a distribuição do grupo quanto às categorias representacionais:

Quadro 82 - Distribuição do grupo quanto às categorias representacionais

\begin{tabular}{|c|c|c|c|}
\hline \multicolumn{2}{|c|}{ Início do ano } & \multicolumn{2}{c|}{ Final do ano } \\
\hline 4 estudantes & 4 categorias & 5 estudantes & CAAP, CAE \\
\hline 2 estudantes & CAAN, CAE & 2 estudantes & $\begin{array}{c}\text { CAAP, CAE, } \\
\text { CAL }\end{array}$ \\
\hline 2 estudantes & $\begin{array}{c}\text { CAAN, CAAP, } \\
\text { CAE }\end{array}$ & r estudante & CAE, CAL \\
\hline
\end{tabular}

Concepções Ancoradas em Aspectos Negativos (CAAN), Concepções

Ancoradas na Escolarização (CAE), Concepções Ancoradas no Letramento

(CAL).

Fonte: Dos/as autores/as.

É possível verificar que a partir da vivência de estudos sistemáticos focados na alfabetização, dentro de uma rotina que dispõe de momentos que visam o despertar do gosto pela leitura e pela produção textual de forma integrada a projetos didáticos, o grupo de estudantes em situação de atraso escolar passou a conceber o ato de ler como algo positivo e vinculado à escola numa perspectiva que suplantou a ideia restrita à junção de letras, realização de atividades escritas e passar de ano, alcançando a esfera da leitura enquanto requisito para a escrita autônoma e autoral. Fato que ratifica a ideia de que "as representações sociais não são apenas tributárias do passado, elas são também passagem para o futuro: está construindo hoje o acervo cognitivo-afetivo com o qual se lidará com o amanhã” (ARRUDA, 2002b, p. 7o).

No caso deste estudo, a partir de novas vivências educativas com/sobre a leitura os/as participantes passaram a (re)elaborar uma nova coleção de sentidos relativos ao ato de ler. Conforme Arruda (2002b), "atribuir sentido é uma delicada operação que demanda terra firme onde jogar a âncora" (p.69), assim, a escola enquanto ambiente voltado para a construção de ideias deve estar atenta aos ancoradouros que oferece ao alunado. Para isso é necessário levar em consideração a subjetividade dos sujeitos. Afinal, é essa subjetividade que faz com que os indivíduos construam concepções diferentes sobre os mesmos objetos sociais. Para Arruda (2002b), essa é a pista que Moscovici (1987) apresenta sobre a relação consubstancial entre representação social e subjetividade, ao 
sinalizar a contribuição de si que cada pessoa apresenta ao mundo para caracterizá-lo. Desse modo, as representações sociais advêm de um processo complexo de produção subjetiva individual e social que assegura a identidade e estabilidade dos sujeitos na realidade na qual acreditam (JODELET, 2018).

\section{CONSIDERAÇÕES FINAIS}

O presente estudo, por ter sido desenvolvido sob o olhar de uma professora pesquisadora a partir de questões de pesquisa suscitadas no bojo de sua práxis, tendo como participantes seus/as próprios/as alunos/as, é um exemplo de como o conhecimento científico no âmbito da educação pode ser construído e reconstruído de forma atrelada à prática. Tornando-se, assim, instantaneamente profícuo. Conhecimento que é, inicialmente, útil aos envolvidos diretamente no estudo e, posteriormente, proveitoso em outros espaços a partir da sua socialização. $O$ estudo deixa sua contribuição ao abordar as relações entre as representações de um objeto (leitura) e a sua aprendizagem (alfabetização), impulsionando reflexões sobre às colaborações da TRS à educação, atribuindo um olhar psicossocial ao processo educativo e às dificuldades presentes nesse percurso.

\section{REFERÊNCIAS}

ALEVATO, Hilda M. R. Qualidade: um mito pós-moderno. In: TEVES, Nilda; RANGEL, Mary (Orgs.). Representação social e educação. Campinas, SP: Papirus, 1999. (Coleção Magistério: Formação e Trabalho Pedagógico).

ANDRÉ, Marli. Etnografia da Prática Escolar. 18. ed. Campinas: Papirus, 2012.

ANGELUCCI, Carla B. et al. O Estado da Arte da Pesquisa sobre o Fracasso Escolar (1991 - 2002): Um Estudo Introdutório. Educação e Pesquisa, São Paulo, v. 30, n.I, p. 51-72, jan./abr. 2004. Disponível em: http://www.scielo.br/pdf/ep/ v3onI/ao4v 30ni.pdf. Acesso em: jun. 2019.

ARRUDA, Angela. As representações sociais: desafios de pesquisa. Revista de Ciências Humanas, Florianópolis: EDIJFSC, Especial Temática, p.09-23, 2002a. Disponível em: https://periodicos.ufsc.br/index.php/revistacfh/article/view/2581o. Acesso em: jun. 2019 .

ARRUDA, Angela. Modernidade \& Cia.: repertórios da mudança. In: JESUÍNO, J. C.; MENDES, F. R. P.; LOPES, M. J. (Orgs.). As representações sociais nas sociedades em mudança. Petrópolis: Vozes, 2015. p. 103-127.

ARRUDA, Angela. Mudança e representação social. Temas em Psicologia da SBP, v. 8, n. 3, p. 241-247, 200o. Disponível em: http://pepsic.bvsalud.org/pdf/tp/v8n3/v8n 3ao3.pdf. Acesso em: jul. 2019.

ARRUDA, Angela. Subjetividade, mudanças e representações sociais. In: FURTADO, O.; REY, F. L. G. (Orgs.). Por uma epistemologia da subjetividade: um debate entre a teoria sócio-histórica e a teoria das representações sociais. São Paulo: Casa do psicólogo, 2002 b, p. 65-75. 
BARDIN, Laurence. Análise de Conteúdo. Lisboa: Edições 70, I979.

BERGER, P. L.; LUCKMANN, T. A Construção Social da Realidade: Tratado de Sociologia do Conhecimento. 24. ed. Petrópolis: Vozes, 2004.

CASTRO, C. R.; CASTRO, M. R. Metáforas no processo de objetivação de representações sociais. Psicologia \& Sociedade, Belo Horizonte, v. 30, 2018. Disponível em: http://dx.doi.org/10.1590/1807-0310/2018v30159429. Acesso em: set. 2018.

CHAIB, Mohamed. Representações sociais, subjetividade e aprendizagem. Cadernos de Pesquisa, São Paulo, v. 45, n. 156, p. 358-372, 2015. Disponível em: http://dx.doi.org/10.1590/198053143201. Acesso em: jul. 2017.

DESLANDES, Suely Ferreira. O projeto de pesquisa como exercício científico e artesanato intelectual. In: MINAYO, M. C. S. (Org.) Pesquisa social: teoria, método e criatividade. 25. ed. Petrópolis: Vozes, 2007. p. 31-6o.

GEORGE, Alexander L.; BENNETT, Andrew. Case Studies and Theory Development in the Social Sciences. Cambridge: MIT Press, 2004.

JODELET, Denise. Problemáticas psicossociais da abordagem da noção de sujeito. Cadernos de Pesquisa, v. 45, n. 156, p. 314-327, abr./jun. 2015. Disponível em: http://publicacoes.fcc.org.br/ojs/index.php/cp/article/view/3203. Acesso em: dez. 2018.

JODELET, Denise. Representações sociais: um domínio em expansão. In: JODELET, D. (Org.). As representações sociais. Rio de Janeiro: EDUERJ, p. I7- 44, 2001.

LAKATOS, E. M.; MARCONI, M. A. Fundamentos de metodologia científica. 5. ed. São Paulo: Atlas, 2003.

MATTOS, Carmen L. G. A abordagem etnográfica na investigação científica. In: MATTOS, C. L. G.; CASTRO, P. A. (Orgs.). Etnografia e educação: conceitos e usos. Campina Grande: EDUEPB, 20II. p. 49-84. Disponível em: http://static. scielo.org/scielobooks/8fcfr/pdf/mattos-9788578791902.pdf. Acesso em: ago. 2017.

MOSCOVICI, Serge. A psicanálise, sua imagem e seu público. Petrópolis: Vozes, 2012.

MOSCOVICI, Serge. Representações sociais: investigações em psicologia social. II. ed. Petrópolis: Vozes, 2015.

OLIVEIRA, Eliana; ENS, Romilda Teodora, ANDRADE, Daniela B. S. F.; MUSSIS, Carlo Ralph. Análise de conteúdo e pesquisa na área da educação. Revista Diálogo Educacional, Curitiba, v. 4, n.9, p.II-27, maio/ago. 2003. Disponível em: https://periodicos.pucpr.br

RICOUER, Paul. A metáfora viva. 2. ed. São Paulo, Edições Loyola, 2005.

SILVA, Gislene S. O. Estado da Arte da Leitura no Brasil: 2010 a 2015. 2017. $170 \mathrm{f}$. Dissertação (Mestrado em Educação) - Universidade Federal de Goiás, Catalão, 2017. 
Disponível em: https://repositorio.bc.ufg.br/tede/bitstream/tede/ 7639/5/ Disserta\% $\mathrm{C}_{3 \%} \mathrm{~A}_{7 \%} \% \mathrm{C}_{3} \% \mathrm{~A}_{30 \%} \quad$ 20-\%20Gislene\%2ode\%20Sousa\%20Oliveira \%20Silva\%20\%202017.pdf. Acesso em: jan. 2018.

SILVA, N. S.; GOMES, A. E. F. "Se Liga" na bicharada: um relato de experiência didática interdisciplinar. In: GUILHERME, W. D. (Org.) Avaliação, políticas e expansão da educação brasileira. v. 9. Ponta Grossa: Atena Editora, 2019.

SOLÉ, Isabel. Estratégias de Leitura. 6. ed. Porto Alegre: Artmed, 1998.

TRIVIÑOS, Augusto N. S. Introdução à Pesquisa em Ciências Sociais: a Pesquisa Qualitativa em Educação - O Positivismo, A Fenomenologia, O Marxismo. São Paulo: Atlas, 1987.

UMAÑA, Sandra Araya. Las representaciones sociales: ejes teóricos para su discusión. Cuaderno de Ciencias Sociales, San José, n. 127, p. 9-82, out. 2002. Disponível em: http://unpani.un.org/intradoc/groups/public/documents/ICAP/ UNPANo27076.pdf Acesso em: 7 jul. 2018.

VELHO, Gilberto. Observando o familiar. In: VELHO, Gilberto. Individualismo e Cultura: Notas para uma antropologia das sociedades contemporâneas. 8. ed. Rio de Janeiro: Jorge Zahar, 2008. p 122-132.

YIN, Robert K. Estudo de Caso: Planejamento e Métodos. 5. ed. São Paulo: Bookmand, 2015 .

ZEICHNER, Kenneth M. Para além da divisão entre professor-pesquisador e pesquisador acadêmico In: GERALDI, C. M.; FIORENTINI, D.; PEREIRA, E. M. (Orgs.). Cartografia do trabalho docente: professor(a)-pesquisador(a). Campinas, Mercado de Letras/ABL, 1998. p. 207-236. 